\section{Genetic Diversity among Cucumis metuliferus Populations Revealed by Cucumber Microsatellites}

\author{
Yiqun Weng \\ Vegetable Crops Research Unit, USDA-ARS, Horticulture Department, \\ University of Wisconsin, 1575 Linden Drive, Madison, WI 53706-1590
}

Additional index words. phylogenetic analysis, African horned cucumber, Cucurbitaceae, simple sequence repeats

\begin{abstract}
Cucumis metuliferus E. Mey. ex Naud (African horned cucumber, horned melon) is endemic to Africa and is a relative of cultivated cucumber (C. sativus $L$.) and melon $(C$. melo $\mathrm{L}$.). In the present study, genetic variation among the USDA $C$. metuliferus collection was evaluated with microsatellite [simple sequence repeat (SSR)] markers derived from $C$. sativus genomic DNA sequences. Of 564 cucumber SSRs tested, $\mathbf{5 1 . 8 \%}$ were able to produce polymerase chain reaction amplicons in $C$. metuliferus suggesting a high degree of DNA sequence homology between the two species. Fortytwo cross-species SSRs were used to assess genetic variation among 36 C. metuliferus accessions. Genetic diversity among these accessions was relatively low. Of the 42 SSRs, 12 were monomorphic, and each marker, on average, was able to detect 3.3 alleles among the 36 accessions. Neighbor-joining clustering analysis revealed a positive relationship between genetic divergence and geographic distances among these accessions. Genetic distance of $C$. metuliferus to melon is smaller than that of $C$. metuliferus to cucumber.
\end{abstract}

The African horned cucumber or horned melon, Cucumis metuliferus $(2 \mathrm{n}=2 x=24)$, is a member of the Cucurbitaceae family, which includes several economically important vegetable crops (cucurbits) like cucumber, melon, squash (Cucurbita ssp.), and watermelon (Citrullus lanatus Matsum. \& Nakai). This monoecious, climbing, annual vine species occurs naturally throughout sub-Saharan regions of Africa and is consumed by some local populations as a vegetable. C. metuliferus fruit is believed to contain antioxidant compounds (Motlhanka, 2008; Wannang et al., 2007). More recently, as a result of the characteristic appealing orange-reddish color and long shelf life of its fruits, $C$. metuliferus is being promoted as a specialty horticultural fruit and has commercial production in several countries, including New Zealand, Israel, Australia, and the United States (National Research Council, 2008; Wilkins-Eller, 2004).

Cucurbit breeders have a strong interest in C. metuliferus because it is a reservoir of potentially useful genes for cucurbit crop improvement. For example, cucumber is highly susceptible to Southern root-knot nematode, Meloidogyne incognita (Kofoid

Received for publication 2 Nov. 2009. Accepted for publication 16 Dec. 2009.

I thank Sanwen Huang of the Chinese Academy of Agricultural Sciences (Beijing, China) for providing sequence information for all primer pairs used in this study and Linda Crubaugh for technical help. I am also indebted to Mike Havey and David Spooner for their valuable comments on the manuscript.

e-mail yiqun.weng@ars.usda.gov orweng4@wisc. edu.

214
Plant materials and simple sequence repeat markers. Thirty-six C. metuliferus accessions, six cucumber, melon, watermelon, and squash (Cucurbita pepo) cultivars or breeding lines, were used. Detailed information on all germplasm used is summa- rized in Table 1 . Of the 36 C. metuliferus accessions, 35 (CM01 to CM35) were from the U.S. National Plant Germplasm System (NPGS) at North Central Region Plant Introduction Station in Ames, IA, and one (CM36) was from a commercial source. The remaining six genotypes included two cucumber lines, 'Gy14' and 'Lemon', two melon lines, 'Top Mark' and 'Q3-2-2', the watermelon cultivar New Hampshire Midget, and one yellow summer crookneck squash line (Table 1). The DNA sample of 'New Hampshire Midget' was provided by Amnon Levi at the USDA-ARS in Charleston, SC.

All simple sequence repeat (SSR) markers were developed from the whole genome sequence of a Chinese cucumber inbred line, '9930' (Huang et al., 2009; Ren et al., 2009) and the primer pairs were synthesized commercially. Initially, 552 genomic SSRs were tested for their ability to amplify CM15 genomic DNA. Among those markers that produced amplicons in CM15, the first 42 were chosen for evaluation of genetic diversity among $C$. metuliferus accessions. Cucumber primer sequence information, SSR motifs, and chromosome locations of the 42 SSR markers are listed in Table 2.

Morphological variation, genomic DNA isolation, and polymerase chain reaction amplification. All plant material was grown in a greenhouse on the University of Wisconsin-Madison campus. Each accession was hand-pollinated to produce seeds for the next generation. Morphological variations in fruits such as fruit skin color, fruit shape, and fruit flesh color among the 36 accessions were recorded.

Genomic DNA was extracted from unexpanded young leaves by the CTAB method (Murray and Thompson, 1980). Each amplification reaction contained $25 \mathrm{ng}$ template DNA, $0.5 \mu \mathrm{M}$ each of two primers, and $1 \times$ polymerase chain reaction (PCR) master mix (Fermentas, Glen Burnie, MD) in a total volume of $10 \mu \mathrm{L}$. A touchdown PCR program (Weng et al., 2005) was used for all primer sets. The majority of tested SSR primer pairs amplified a single band from each sample, and the variation in the size of the PCR products allowed the patterns to be resolved in $3 \%$ agarose gels stained with ethidium bromide. Markers detecting null alleles in PCR were repeated at least once to rule out the possibility of PCR failure.

Data analysis. The discriminatory power of each marker was assessed with Polymorphic Information Content (PIC). PIC was calculated as PIC $=1-\sum\left(\mathrm{p}_{\mathrm{i}}{ }^{2}\right)$, in which $\mathrm{p}_{\mathrm{i}}$ is the frequency of the $i$ th allele detected in all 36 C. metuliferus accessions (Anderson et al., 1992).

PCR products were scored in binary format with the presence of a band being scored as 1 and its absence scored as 0 , thus generating a binary matrix, which was used in data analysis with the software package PHYLIP 3.66 (Felsenstein, 1989). Specifically, 1000 bootstrap trials were performed on the data using SEQBOOT after which RESTDIST was used to construct pairwise 
Table 1. Plant materials used in this study.

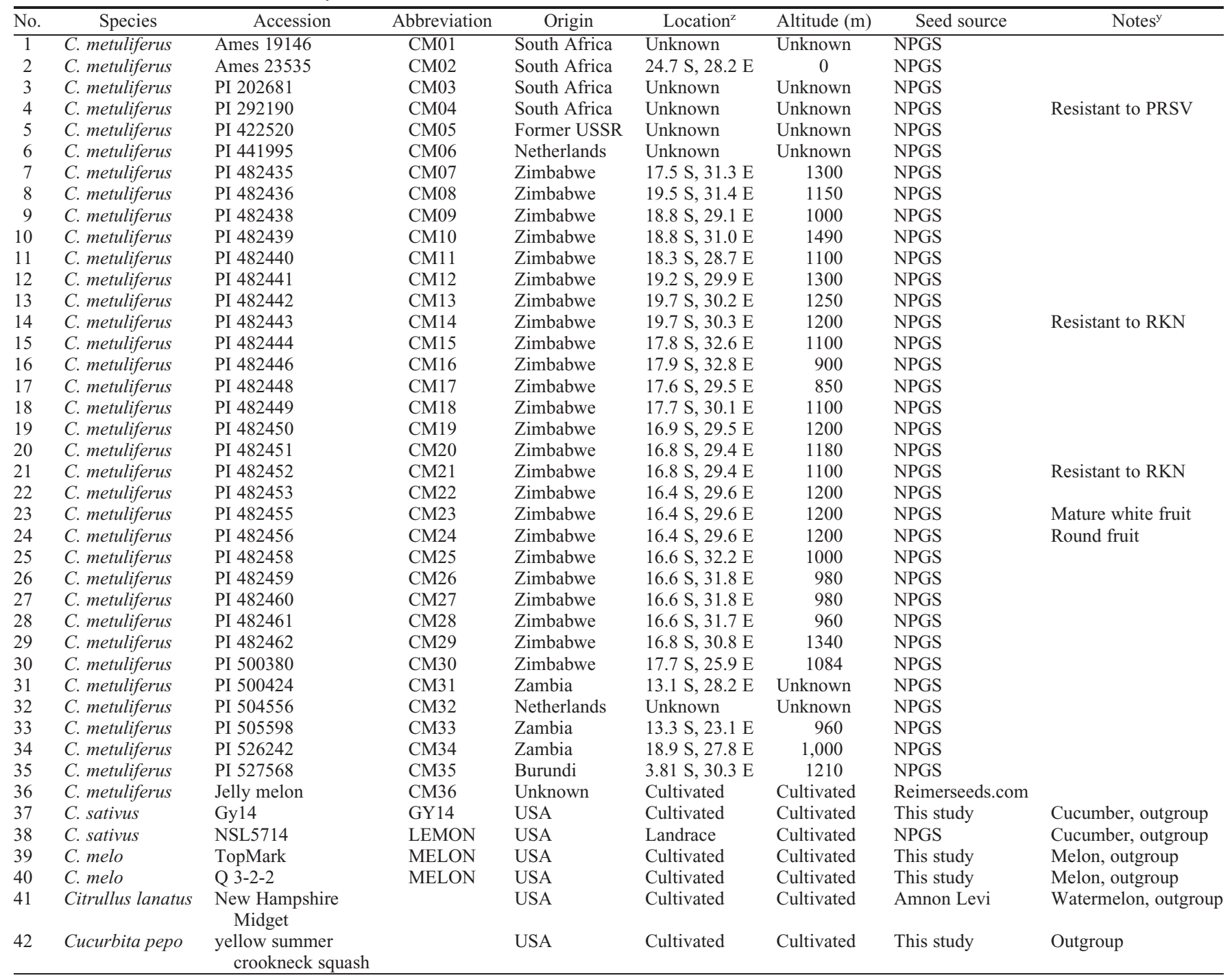

${ }^{2}$ Geographic ordinate information was from USDA Germplasm Resource Information Network web site (http://www.ars-grin.gov/). S = south (altitude); E = east (latitude).

yPRSV= papaya ringspot virus (Provvidenti and Gonsalves, 1982); RKN = root-knot nematode (Walters et al., 1993).

distance matrices (based on $\mathrm{Nei}$ and $\mathrm{Li}$, 1979), then subjected to neighbor-joining (NJ) cluster analysis (Saitou and Nei, 1987) from which a consensus tree was generated with CONSENSE. Non-C. metuliferus species were used as outgroups in tree construction.

The binary data matrix was also used to calculate Jaccard's similarity coefficients (Jaccard, 1901) to estimate the genetic diversity among the $C$. metuliferus accessions and between these and the outgroup members. Genetic distance estimates were calculated as the complement of Jaccard's similarity coefficient (Spooner et al., 1996).

\section{Results}

Morphological variation among C. metuliferus accessions. Under greenhouse conditions, all C. metuliferus plants were monoecious with staminate flowers typically appearing several days before pistillate flowers, but variation in flowering time (days from germination to anthesis) among these lines was observed. Most female flowers and fruits were concentrated at the base of the vines. The immature fruits were dark green with mottled green spots. Ripened fruits were typically and characteristically ellipsoid in shape and bright reddish orange in color with large, sharp spines. All mature fruits had green flesh color, but variation in fruit shape and color was observed. CM23 (PI 482455) had white immature fruit, which turned pale yellow when ripe. CM24 (PI 482456) had round mature fruits.

Cross-species transferability of cucumber genomic simple sequence repeats. Initially, 552 cucumber genomic SSRs were examined for their ability to amplify genomic DNA of CM15. A total of 284 primer pairs amplified PCR products in CM15 yielding a $51.8 \%$ success rate of amplification. The first 42 of the 284 SSRs were further tested in an additional 41 cucurbit lines described in Table 1. As expected, all SSRs had successful amplification in 36 C. metuliferus accessions as well as 'Gy14' and 'Lemon' cucumbers. Cross-species transferability of the $42 \mathrm{cu}-$ cumber SSRs across melon, watermelon, and squash was $83.3 \%$ (35 of 42), $45.0 \%$ (19 of 42 ), and $50.0 \%$ (21 of 42), respectively. The PCR amplification details for each marker are shown in Table 2.

A total of 209 putative alleles was revealed by the 42 SSRs generated from 41 DNA templates. Each of the 42 primer pairs amplified a single band in 'Gy14' or 'Lemon'. In 'Top Mark' melon, seven markers failed to amplify; two markers, SSR01115 and SSR04534, amplified two and three bands, respectively; and the remaining 33 each amplified one band (Table 2). In C. metuliferus, 33 of 42 SSRs each amplified a single band; nine amplified two or three bands in each DNA template, of which SSR01115 and SSR04534 had two to three bands in all accessions, whereas the remaining seven markers (SSR00004, SSR00931, SSR01178, 
Table 2. Primer sequence information, chromosome location, PIC, and number of PCR bands in four cucurbit crop species of 42 SSRs used in this study.

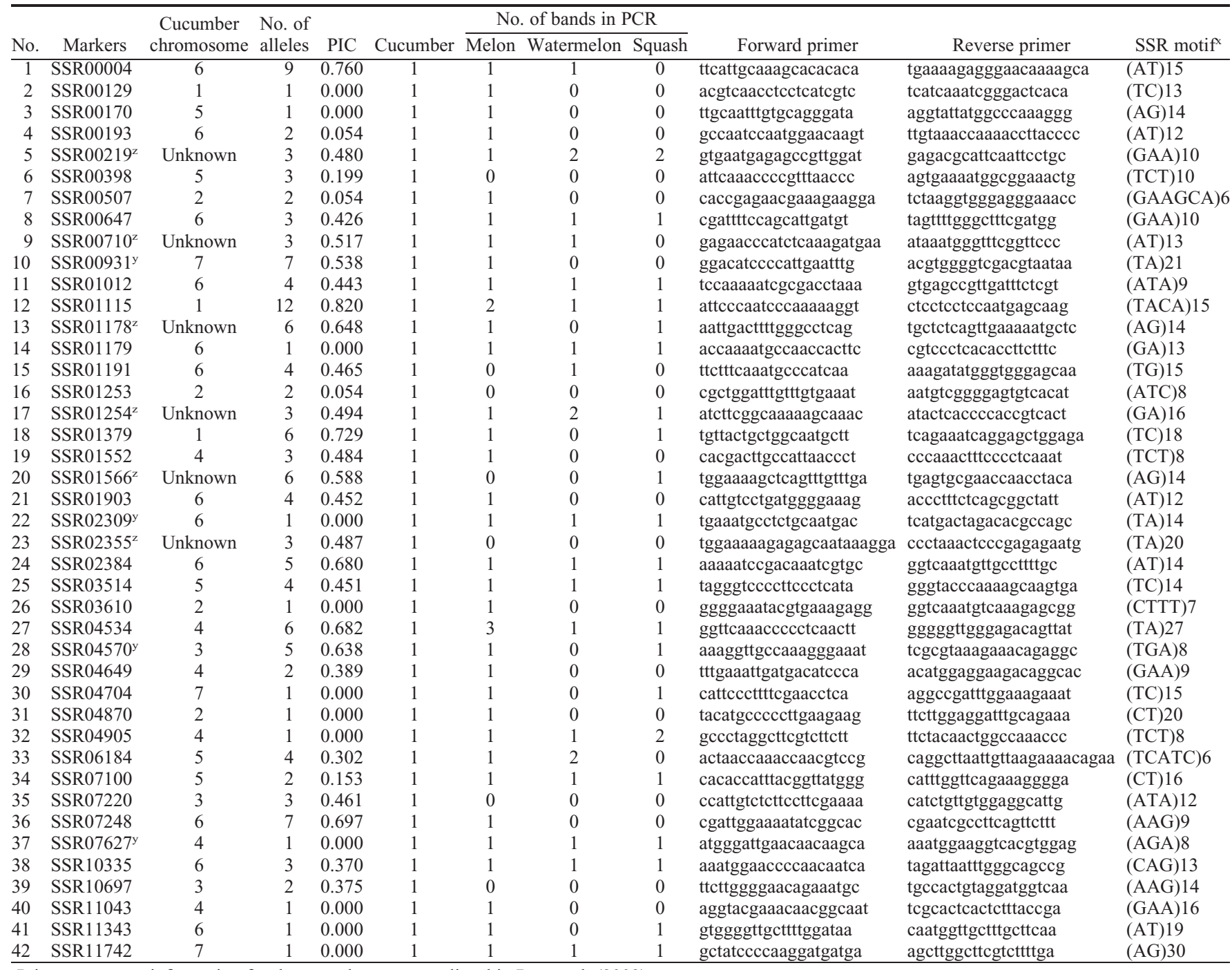

${ }^{2}$ Primer sequence information for these markers was not listed in Ren et al. (2009).

${ }^{y}$ Chromosome location information for these markers was from Weng et al. (unpublished data).

${ }^{\times}$Repeat numbers of motifs shown were in the Chinese cucumber inbred line 9930 (Ren et al., 2009).

$\mathrm{PIC}=$ Polymorphic Information Content; $\mathrm{PCR}=$ polymerase chain reaction; SSR = simple sequence repeat.

SSR01552, SSR03514, SSR04570, and SSR06184) amplified more than one band in only some accessions, which may suggest heterozygosity at these SSR loci.

The 42 SSRs detected 140 putative alleles among 36 C. metuliferus accessions with an average of 3.33 alleles per SSR locus (Table 2). Twelve of the 42 markers were not informative among the 36 accessions. The PIC values of these markers ranged from 0 to 0.820 with the average of 0.331 across 42 markers (Table 2).

Genetic diversity of $C$. metuliferus accessions. Bootstrapping and NJ cluster analysis resulted in a consensus tree as shown in Figure 1. Not all branch points in the consensus tree were strongly supported. Of the 1000 bootstraps, those supported by more than $50 \%$ probability were mostly inner nodes. Nevertheless, it is evident that most of the 36 C. metuliferus accessions were grouped according to their geographic origins. Six groups (A through F in Fig. 1) could be recognized in the dendrogram. Accessions that were collected from nearby locations were clustered in the same group (Table 1).

Several accessions, including CM31 (PI 500424), CM 33 (PI 505598), CM34 (PI 526242), and CM35 (PI 527268), were collected from relatively isolated locations (Table 1). CM31 and CM33 were from Zambia and consistent with this, they were clustered in one group. However, CM34 and CM35 and a commercial line, CM36, were placed in the same Group E, although they were geographically distant from each other.

For CM05, CM06, and CM32, their geographic coordinate information was not available in the NPGS database. Clustering analysis placed CM05 and CM06 in Group A with four accessions from South Africa, and CM32 was in the same group with CM31 and CM33 (Fig. 1).

The Jaccard's similarity coefficient-based genetic distances among tested materials were calculated. The genetic distance matrix between 11 selected $C$. metuliferus accessions and two outgroup members ('Gy14' and 'Top Mark') is listed in Table 3, which agreed very well with the consensus tree (Fig. 1). From Table 3 , it is evident that the genetic distance from $C$. metuliferus to C. melo (cv. Top Mark) was smaller than that to cucumber (cv. Gy14). Although the genetic distance between melon and cucumber was 0.933 , that between $C$. metuliferus and melon was 0.897 and between $C$. metuliferus and cucumber was 0.954 (average across 11 accessions in Table 3) suggesting $C$. metuliferus is more similar to C. melo than to C. sativus.

\section{Discussion}

In this study, the genetic variation of USDA C. metuliferus collections was evaluated using molecular markers. Data obtained here suggested that genetic diversity among the examined $C$. metuliferus populations was relatively low. The $42 \mathrm{SSR}$ were able to detect on average 3.3 alleles across $36 C$. metuliferus accessions, and 12 of them were monomorphic. Considering that $C$. metuliferus 


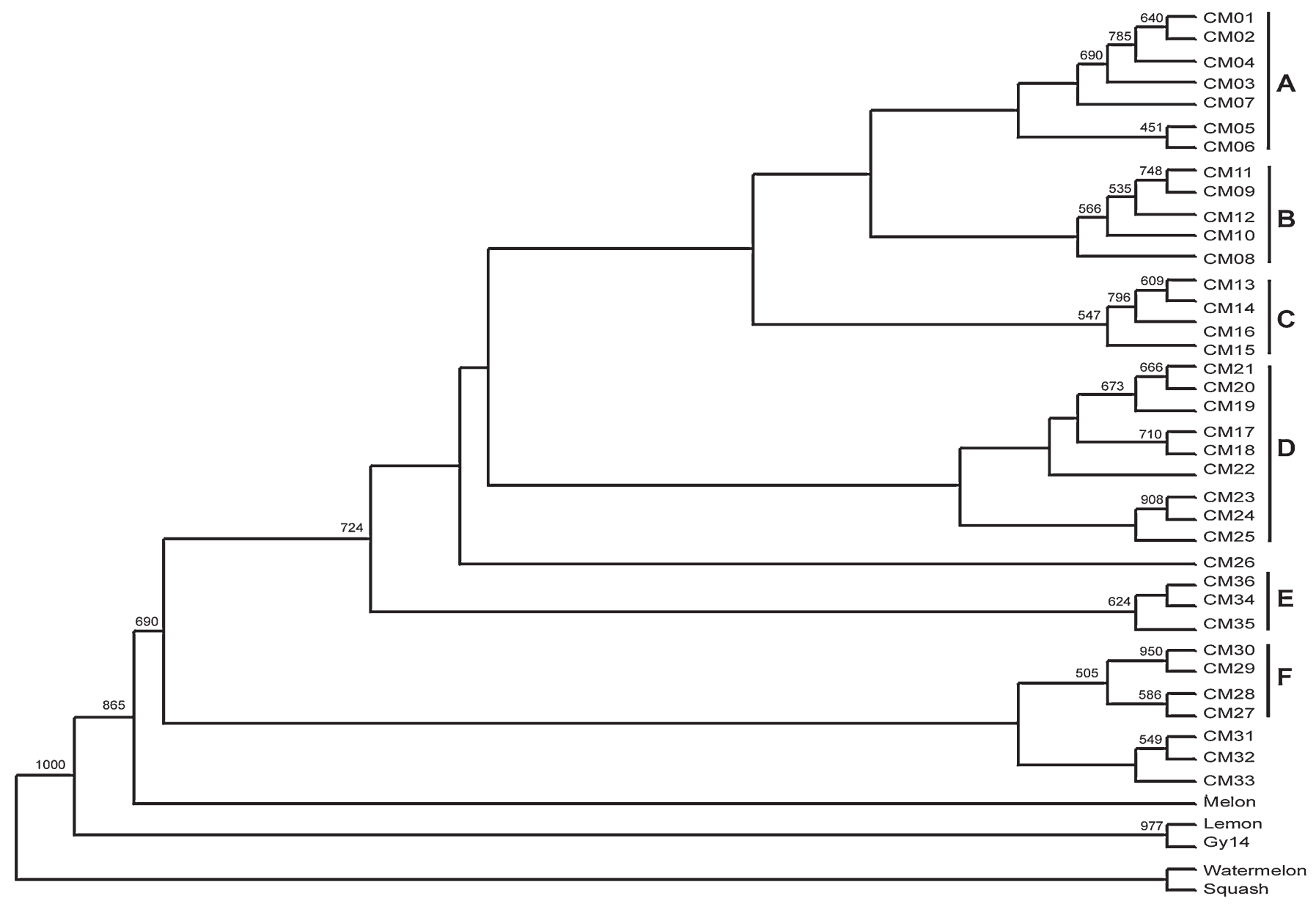

Fig. 1. Dendrogram of 36 C. metuliferus accessions based on 42 cucumber (C. sativus) genomic simple sequence repeat markers. Accession numbers were shown to the immediate right of the dendrogram branches. Bootstrap sampling of alleles was carried out for 1000 repetitions. Only percentages of those supporting nodes with more than $50 \%$ probability were shown. Accessions delimited by vertical bars and capital letters are member of cluster from the same geographic region.

Table 3. Jaccard's similarity coefficient-based genetic distance matrix among 11 selected C. metuliferus accessions, 'Gy14' cucumber and 'Top Mark' melon.

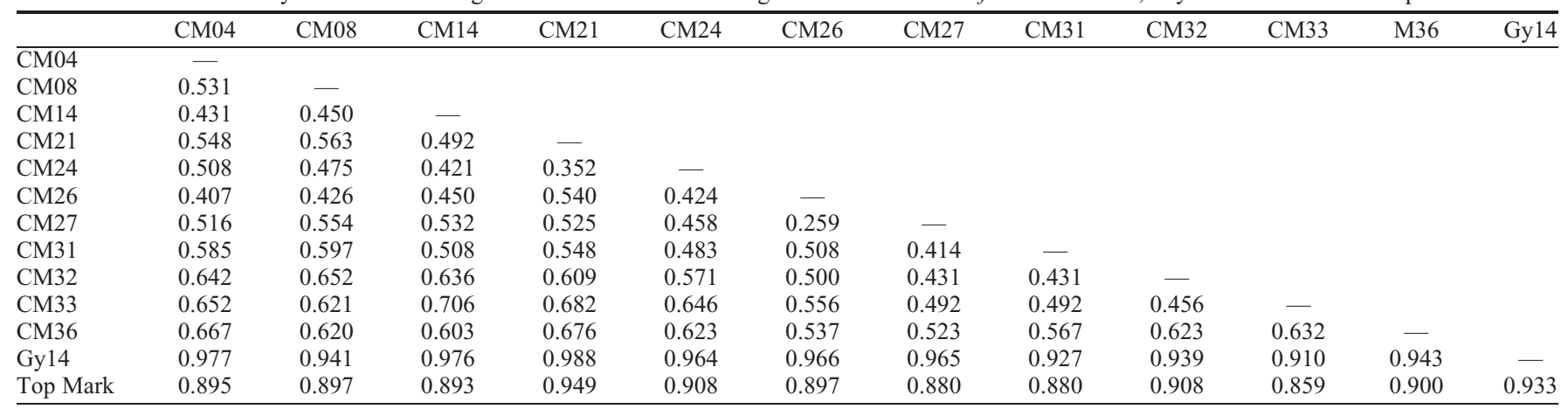

is indigenous to Africa, which was thought to be the center of Cucumis evolution (Kirkbride, 1993), this low level of diversity was unexpected. The markers used were selected based on their transferability to C. metuliferus. It may be argued that this selection process might bias toward those evolutionarily conserved DNA sequences and underestimate genetic variation because conserved sequences tend to be less polymorphic across taxa (e.g., Sourdille et al., 2001; Yu et al., 2004; Zhang et al., 2005). If this is true, low polymorphism should also be expected in cucumber and melon for these markers, which was not the case. Each of the 42 markers amplified a single DNA fragment in the two cucumber lines, 'Gy14' and 'Lemon'. The polymorphism between them was $33.3 \%$ (14 of 42 ), which was much higher than the overall polymorphism reported among cucumber lines ( $7 \%$ to $12 \%)$ using other marker types (Dijkhuizen et al., 1996; Staub et al., 2002). Meanwhile, the polymorphism rate of 30 SSRs between 'Top Mark' and 'Q3-2-2' melons was 20\% (six of 30 ), which was comparable to that reported by Cuevas et al. $(2008,2009)$. Therefore, the marker selection process used in this study did not seem to contribute to the observed low genetic diversity among the $C$. metuliferus accessions.

One possible explanation for the low diversity is the sample size examined in this study. C. metuliferus is endemic to the vast areas from South Africa to tropical Africa (National Research Council, 2008; WilkinsEller, 2004). However, only 36 C. metuliferus accessions are currently available in NPGS. Thirty-three of the 35 accessions used in this 
study came from only four countries, 24 of which were collected in a relatively concentrated area in Zimbabwe (Table 1). It is possible that the genetic diversity of the whole $C$. metuliferus population might not be well represented by the accessions examined. Nevertheless, it seems that low genetic diversity is common among cucurbits as compared with other crop species. For example, in genetic diversity studies with rice, Oryza sativa L. (Ni et al., 2002), cotton, Gossypium hirsutum L. (Lacape et al., 2007), or soybean, Glycine max (L.) Merr. (Kuroda et al., 2009), the average number of alleles per marker locus revealed by different marker types (mainly SSRs) was generally over 5.0, which was even higher among their respective wild relatives. This number was far fewer (less than 3.5) in cucurbit crops like cucumber (Staub et al., 2002; Watcharawongpaiboon and Chunwongs, 2008), melon (Lpez-Sese et al., 2003; Luan et al., 2008; Nakata et al., 2005; Tanaka et al., 2007), watermelon (Levi et al., 2001), and $C$. metuliferus (this study). Allard (1960) explained that because cucurbit plants are large and require a lot of space to grow, a few plants are likely to satisfy the wants of any one grower. Cucurbits may consequently have existed in small colonies both in nature and under cultivation, and this restriction in population size may have produced inbreeding (and reduced heterozygosity) despite the monoecious floral mechanism favoring outcrossing. It is not known if the low genetic variation represents a bottleneck during the evolution of $C$. metuliferus.

The primary motivation for the present study was to evaluate genetic diversity among the $C$. metuliferus accessions, thus providing some guidance for exploring this gene pool for cucumber and melon improvement. Early attempts of wide hybridization between C. metuliferus and melon or cucumber were unsuccessful (Deakin et al., 1971; Fassuliotis, 1977, 1979; Walters and Wehner, 2002). An alternative strategy may be through comparative genetic mapping of target genes such as nematode resistance in C. metuliferus using cross-species molecular markers. The transferability of molecular markers developed in cucumber is usually more than $50 \%$ across other Cucumis species (Ren et al., 2009; this study). A large amount of molecular markers can be developed from whole genome sequences of cucumber or melon (Gonzalez et al., 2009; Huang et al., 2009), which can be used for molecular mapping of interested genes or quantitative trait loci (for example, nematode resistance genes) in $C$. metuliferus. The target genes could then be cloned from C. metuliferus and transferred into cultivated cucurbit crops through biotechnological approaches.

Despite the generally low genetic diversity among the 36 C. metuliferus accessions, the polymorphism level between specific accessions was adequate for genetic mapping. For example, among the 42 SSR markers, the polymorphism level between CM33 (PI 505598) with CM04 (PI292120, resistant to papaya ringspot virus) and CM14 (PI 482443, resistant to root-knot nematode) (Walters et al., 1993) was $45.4 \%$ and $50.0 \%$, respectively. Considering the availability of large numbers of molecular markers from cucumber or melon, this level of polymorphism makes it relatively straightforward to construct a linkage map in C. metuliferus to locate target resistance loci.

\section{Literature Cited}

Allard, R.W. 1960. Principles of plant breeding. John Wiley \& Sons, Inc., New York, NY. p. 38.

Anderson, J.A., G.A. Churchill, J.E. Autrique, S.D. Tanksley, and M.E. Sorrells. 1992. Optimizing parental selection for genetic linkage maps. Genome 36:181-186.

Benzioni, A., S. Mendlinger, M. Ventura, and S. Huskens. 1991. The effect of sowing dates and temperatures on germination, flowering and yield of Cucumis metuliferus. HortScience 26: 1051-1053.

Cuevas, H.E., J.E. Staub, P.W. Simon, and J.E. Zalapa. 2009. A consensus linkage map identifies genomic regions controlling fruit maturity and beta-carotene-associated flesh color in melon (Cucumis melo L.). Theor. Appl. Genet. 119:741-756.

Cuevas, H.E., J.E. Staub, P.W. Simon, J.E. Zalapa, and J.D. McCreight. 2008. Mapping of genetic loci that regulated quantity of beta-carotene in fruit of U.S. Western Shipping melon (Cucumis melo L.). Theor. Appl. Genet. 117:1345-1359.

Deakin, J.R., G.W. Bohn, and T.W. Whitaker. 1971. Interspecific hybridization in Cucumis. Econ. Bot. 25:195-211.

Dijkhuizen, A., W.C. Kennard, M.J. Havey, and J.E. Staub. 1996. RFLP variation and genetic relationships in cultivated cucumber. Euphytica 90:79-89.

Fassuliotis, G. 1967. Species of Cucumis resistant to the root-knot nematode, Meloidoyne incognita Acrita. Plant Dis. Rep. 51:720-723.

Fassuliotis, G. 1977. Self-fertilization of Cucumis metuliferus Naud., and its cross-compatibility with C. melo L. J. Amer. Soc. Hort. Sci. 102: 336-339.

Fassuliotis, G. 1979. Plant breeding for root-knot nematode resistance, 425-453. In: Sasser, J.D. and C.C. Carter (eds.). Root-knot nematodes (Meloidogyne species): Systematics, biology and control. Academic Press, New York, NY.

Felsenstein, J. 1989. PHYLIP-Phylogeny Inference Package (Version 3.2). Cladistics 5:164166.

Gonzalez, V., G. Mir, P. Arús, P. Puigdomènech, and J. Garcia-Mas. 2009. Towards the whole sequence of the melon genome. Abstract of XVII Plant and Animal Genome Conf; 10-14 Jan.; San Diego, CA. 24 Jan. 2010. <http://www. intl-pag.org/>.

Huang, S., R.Q. Li, Z.H. Zhang, L. Li, X.F. Gu, W. Fan, W.J. Lucas, and X.W. Wang, et al. 2009. The genome of the cucumber, Cucumis sativus L. Nat. Genet. 41:1275-1281.

Jaccard, P. 1901. Étude comparative de la distribution florale dans une portion des Alpes et des Jura. Bulletin del la Société Vaudoise des Sciences Naturelles 37:547-579.

Kirkbride, J.H. 1993. Biosystematic monograph of the genus Cucumis (Cucurbitaceae). Parkway Publishers, Boone, NC.

Kho, Y.O., A.M.P. den Nijs, and J. Franken. 1980. Interspecific hybridization in Cucumis. II. The crossability of species, an investigation of in vivo pollen tube growth and seed set. Euphytica 29:661-672.
Kroon, G.H., J.B.M. Custers, Y.O. Kho, and A.M.P. den Nijs. 1979. Interspecific hybridization in Cucumis L. I. Need for genetic variation, biosystematic relations and possibilities to overcome crossing barriers. Euphytica 28:723-728.

Kuroda, Y., N. Tomooka, A. Kaga, S.M.S.W. Wanigadeva, and D.A. Vaughan. 2009. Genetic diversity of wild soybean (Glycine soja Sieb. et Zucc.) and Japanese cultivated soybeans [G. $\max (\mathrm{L}$.) Merr.] based on microsatellite (SSR) analysis and the selection of a core collection. Genet. Resources Crop Evol. 56: 1045-1055.

Lacape, J.M., E.D. Dessauw, E.M. Rajab, J.L. Noyer, and E.B. Hau. 2007. Microsatellite diversity in tetraploid Gossypium germplasm: Assembling a highly informative genotyping set of cotton SSRs. Mol. Breed. 19:45-58.

Levi, A., C.E. Thomas, T.C. Wehner, and X.P. Zhang. 2001. Low genetic diversity indicates the need to broaden the genetic base of cultivated watermelon. HortScience 36:1096-1101.

Lpez-Sese, A.I., J.E. Staub, and M.L. GomezGuillamon. 2003. Genetic analysis of Spanish melon (Cucumis melo L.) germplasm using a standardized molecular-marker array and geographically diverse reference accessions. Theor. Appl. Genet. 108:41-52.

Luan, F.S., I. Delannay, and J.E. Staub. 2008. Chinese melon (Cucumis melo L.) diversity analyses provide strategies for germplasm curation, genetic improvement, and evidentiary support of domestication patterns. Euphytica 164:445-461.

Motlhanka, D.M.T. 2008. Free radical scavenging activity of selected medicinal plants of Eastern Botswana. Pak. J. Biol. Sci. 11:805-808.

Murray, M.G. and W.F. Thompson. 1980. Rapid isolation of high molecular weight DNA. Nucleic Acids Res. 8:4321-4325.

Nakata, E., J.E. Staub, A.I. Lopez-Sese, and K. Nurit. 2005. Genetic diversity of Japanese melon cultivars (Cucumis melo L.) as assessed by random amplified polymorphic DNA and simple sequence repeat markers. Genet. Resources Crop Evol. 52:405-419.

National Research Council. 2008. Horned melon, p. 89-101. Lost crops of Africa. Vol. III: Fruits. The National Academic Press, Washington DC.

Nei, M. and W. Li. 1979. Mathematical model for studying genetic variation in terms of restriction endonucleases. Proc. Natl. Acad. Sci. USA 76:5269-5273.

Ni, J., P.M. Colowit, and D.J. Mackill. 2002. Evaluation of genetic diversity in rice subspecies using microsatellite markers. Crop Sci. 42:601-607.

Norton, J.D. and K.R. Barker. 1980. Characteristics of progeny from an interspecific cross of Cucumis melo with C. metuliferus. J. Amer. Soc. Hort. Sci. 105:174-180.

Nugent, P.E. and P.D. Dukes. 1997. Root-knot nematode resistance in Cucumis species. HortScience 32:880-881.

Provvidenti, R. and D. Gonsalves. 1982. Resistance to papaya ringspot virus in Cucumis metuliferus and its relationship to resistance to watermelon mosaic virus-1. J. Hered. 73:239-240.

Provvidenti, R. and R.W. Robinson. 1974. Resistance to squash mosaic virus 1 in Cucumis metuliferus. Plant Dis. Rep. 58:735-738.

Ren, Y., Z.H. Zhang, J.H. Liu, J.E. Staub, Y.H. Han, Z.C. Cheng, X.F. Li, J.Y. Lu, H. Miao, H.X. Kang, B.Y. Xie, X.F. Gu, X.W. Wang, Y.C. Du, W.W. Jin, and S.W. Huang. 2009. An integrated genetic and cytogenetic map of the cucumber genome. PLoS One 4:e5795. 
Saitou, N. and M. Nei. 1987. The neighbor-joining method: A new method for reconstructing phylogenetic trees. Mol. Biol. Evol. 4:406-425.

Sourdille, P., M. Tavaud, G. Charmet, and M. Bernard. 2001. Transferability of wheat microsatellites to diploid Triticeae species carrying the A, B and D genomes. Theor. Appl. Genet. 103:346-352.

Spooner, D.M., J. Tivang, J. Nienhuis, J.T. Miller, D.S. Douches, and M.A. Contreras. 1996. Comparison of four molecular markers in measuring relationships among the wild potato relatives Solanum section Etuberosum (subgenus Potato). Theor. Appl. Genet. 92:532-540.

Staub, J.E., F. Dane, K. Reitsma, G. Fazio, and A. Lopez-Sese. 2002. The formation of test arrays and a core collection in cucumber using phenotypic and molecular marker data. J. Amer. Soc. Hort. Sci. 127:558-567.

Tanaka, K., A. Nishitani, Y. Akashi, H. Yoshino, and K. Kato. 2007. Molecular characterization of South and East Asian melon, Cucumis melo
L., and the origin of Group Conomon var. makuwa and var. conomon revealed by RAPD analysis. Euphytica 153:233-247.

Walters, S.A. and T.C. Wehner. 2002. Incompatibility in diploid and tetraploid crosses of Cucumis sativus and Cucumis metuliferus. Euphytica 128:371-374.

Walters, S.A., T.C. Wehner, and R.B. Baker. 1993 Root-knot nematode resistance in cucumber and horned cucumber. HortScience 28:151-154.

Walters, S.A., T.C. Wehner, M.E. Daykin, and R.B. Baker. 2006. Penetration rates of rootknot nematodes into Cucumis sativus and $C$. metuliferus roots and subsequent histological changes. Nematropica 36:231-242.

Wannang, N.N., N.S. Jimam, S. Omale, M.L.P. Dapar, S.S. Gyang, and J.C. Aguiyi. 2007. Effects of Cucumis metuliferus (Cucurbitaceae) fruits on enzymes and haematological parameters in albino rats. Afr. J. Biotechnol. 6:2515-2518.

Watcharawongpaiboon, N. and J. Chunwongs. 2008. Development and characterization of microsatellite markers from an enriched genomic library of cucumber (Cucumis sativus). Plant Breed. 127:74-81.

Weng, Y., W. Li, R.N. Devkota, and J.C. Rudd. 2005. Microsatellite markers associated with two Aegilops tauschii-derived greenbug resistance loci in wheat. Theor. Appl. Genet. 110: $462-469$.

Wilkins-Eller, M.H. 2004. Cucumis metuliferus E.Mey. ex Naud. [Internet] Record from Protabase. In: Grubben, G.J.H. and O.A. Denton (eds.). PROTA (Plant Resources of Tropical Africa), Wageningen, The Netherlands. 24 Jan. 2010. <http://database.prota.org/search.htm>.

Yu, J.K., M. La Rota, R.V. Kantety, and M.E. Sorrells. 2004. EST derived SSR markers for comparative mapping in wheat and rice. Mol. Genet. Genomics 271:742-751.

Zhang, L.Y., M. Bernard, P. Leroy, C. Feuillet, and P. Sourdille. 2005. High transferability of bread wheat EST-derived SSRs to other cereals. Theor. Appl. Genet. 111:677-687. 